\title{
Laparoscopic hernia repair reduced recovery time and days of postoperative analgesia use better than Shouldice repair
}

Juul P, Christensen K. Randomized clinical trial of laparoscopic versus open inguinal hernia repair. Br J Surg 1999 Mar;86:316-9.

QUESTION: In men with a primary unilateral hernia, is laparoscopic repair better than Shouldice repair for shortening recovery time without increasing the complication and recurrence rates?

\section{Design}

Randomised (allocation concealed*), unblinded,* controlled trial with a median follow-up of 12 months.

\section{Setting}

The surgical department of a district hospital in Nyborg, Denmark.

\section{Patients}

287 men who were $18-75$ years of age, had a primary unilateral hernia, and were referred for elective surgery. Exclusion criteria were irreducible hernias and unfitness for general anaesthesia. 268 patients (93\%, median age 48 y) were assessed at 1 month; follow-up at 24 months was $91 \%$.

\section{Intervention}

Patients were allocated to transabdominal preperitoneal laparoscopic repair $(n=146)$ or open hernia repair $(\mathrm{n}=141)$. In the laparoscopic group, a $10-\mathrm{cm} \times 15-\mathrm{cm}$ polypropylene mesh widely overlapped the defect and was fixed with staples to the Cooper ligament and anteriorly to the abdominal wall. Conventional repair was done under general or spinal anaesthesia and consisted either of a modified Shouldice technique or a sutured narrowing of the internal ring in men with small indirect hernias and intact inguinal floors.

\section{Main outcome measures}

Complications, recurrences, length of recovery period, and postoperative pain.

\section{Main results}

Groups did not differ for recurrence or complication rates (table). Men in the laparoscopic group returned to complete normal activities sooner (median $13 v 18 \mathrm{~d}$, $\mathrm{p}<0.005)$ and used postoperative analgesia for a shorter period (median $2.1 v 2.7 \mathrm{~d}, \mathrm{p}<0.02$ ) than did those in the conventional-repair group.

\section{Conclusion}

In men with a primary unilateral hernia, laparoscopic repair shortened recovery time and days of postoperative analgesia use and led to rates of complication and recurrence similar to those of Shouldice repair.

\footnotetext{
* See glossary.
}

\section{COMMENTARY}

The randomised controlled trial by Juul and Christensen compares laparoscopic repair with Shouldice repair for primary unilateral hernia. The sample size is adequate to detect clinically significant differences between the surgical procedures. The authors conclude that laparoscopic repair results in a shorter duration of surgery, decreased postoperative analgesic use, and a quicker resumption of activities, including return to work.

This study improves on previous literature because it contains uniform data on unilateral hernias being treated for the first time. However, the study had two shortcomings: not all patients were followed for a long period, and the natural history of the disease includes recurrences later than 1 year. The authors have added this caveat and should report the ongoing results of this study in 5 years. An economic analysis with respect to the hospital costs would benefit those seeking to use the specialised equipment for laparoscopic repair.

From the perspective of a practising clinician, the issue is whether the increased benefits of laparoscopic surgery in the long and short term justify the investments of time and money required to learn the technique. Another issue relates to the individual learning curve: Can a single surgeon replicate the results of an experienced group of surgeons? In the absence of data relating to the learning curve for this group of surgeons, an individual surgeon wishing to make a change should expect a higher complication rate in the short term and weigh this against the potential benefits in the future for the patient.

If I were a surgeon using the Shouldice technique, the results of this study would interest me, but I would defer changing to laparoscopic repair until the long-term results showed clear superiority over Shouldice repair.

Michael Gross, MD Dalhousie University Halifax, Nova Scotia, Canada

Source of funding: no external funding.

For correspondence: Dr P Juul, Department of Surgery, Nyborg Hospital, 5800 Nyborg, Denmark. FAX +45-6331-2801.

Laparoscopic repair $v$ Shouldice repair for primary unilateral inguinal hernias at median follow-up of 12 monthst

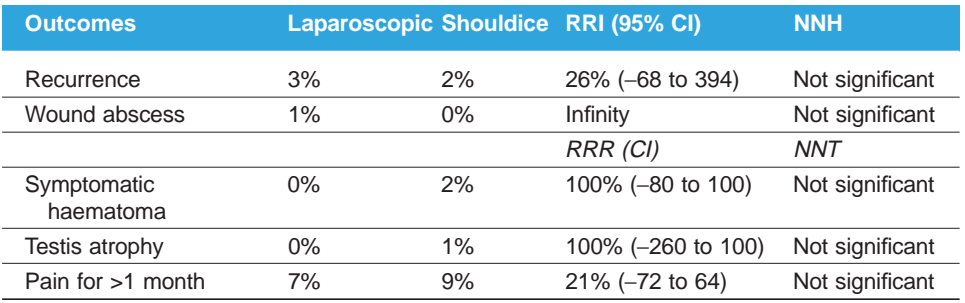

†Abbreviations defined in glossary; RRR, RRI, NNT, NNH, and $\mathrm{Cl}$ calculated from data in article. 